\title{
Study of Radiation Effects on Upland Cotton (Gossypium hirsutum L.) Pollen Grain Irradiated by ${ }^{60} \mathrm{Co}-\gamma$ Ray
}

\author{
Jieyu Yue ${ }^{1} \&$ Jinhua Zou ${ }^{1}$ \\ ${ }^{1}$ Key Laboratory of Cytogenetical and Molecular Regulation, College of Life Science, Tianjin Normal \\ University, Tianjin 300387, China
}

Correspondence: Jieyu Yue, Key Laboratory of Cytogenetical and Molecular Regulation, College of Life Science, Tianjin Normal University, Tianjin 300387, China. E-mail: yueshan1982@163.com

Received: March 5, 2012 Accepted: March 22, 2012 Online Published: May 22, 2012

doi:10.5539/jas.v4n7p85 URL: http://dx.doi.org/10.5539/jas.v4n7p85

This work was supported by the Science and Technology Development foundation Program of University in Tianjin (20110603, 20100606), Doctoral Foud of Tianjin Normal University (52XB1105) and Open Foud of Tianjin Key Lab Cytogenet \& Mol Regulat.

\begin{abstract}
This paper studied the effects of ${ }^{60} \mathrm{Co}-\gamma$ ray on the pollen grains of upland cotton. The irradiation effects on pollen grains were tested in terms of the ultrastructural changes in the exine and interior of pollen grains, their germination rate, the single primer amplification reaction polymorphism of ovule developed after the pistils were pollinated by the pollen grains which had been irradiated with ${ }^{60} \mathrm{Co}-\gamma$ ray, and the law of genetic variation of their $\mathrm{M}_{1}, \mathrm{M}_{2}$ progeny. The results showed that ${ }^{60} \mathrm{Co}-\gamma$ ray had no effects on the exine wall of the pollen grains. The interior structure of pollen grain were destroyed significiantly. The interior wall became thin and irregular, and part of it concavitied to the inner. The endoplasmic reticulum depolymerized. The amount and the density of pollen grain inclusions increased. The number of pollen tubes in style decreased by $38 \%$, compared with the control group (natural pollen grain). The single primer amplification reaction polymorphism of ovule increased. The germination percentage of $\mathrm{M}_{1}$ progeny was decreased by $41.03 \%$. And with the cotton plants of $\mathrm{M}_{1}$ progeny, the length of taproot, longest lateral root, average lateral root, the number of lateral root, and the height of seedling decreased by $22.24 \%, 18.93 \%, 11.80 \%, 28.02 \%, 23.05 \%$, respectively, compared with the control group. The percentage of sterility plants was $56.7 \%$. The coefficients of variations of boll number, lint percentage, perimeter of stem, seed index, fruit branch number, longissimus fruit branch and plant height increased by $103.206 \%, 74.588 \%, 75.96 \%, 69.83 \%, 33.25 \%$ and $29.624 \%, 11.843 \%$, respectively., compared with the control group. With the cotton plants of $\mathrm{M}_{2}$ progeny, the percentage of sterility plants was $56.7 \%$. And the coefficients of variations of boll number, seed cotton yield, fruit branch number, plant height, boll height, and lint percentage increased by $21.944 \%, 16.261 \%, 3.827 \%, 3.986 \%, 7.25 \%$ and $0.497 \%$, respectively., compared with the control group. The coefficients of variations and change range of agronomic traits in $\mathrm{M}_{2}$ progeny were less than them in $\mathrm{M}_{1}$ progeny.
\end{abstract}

Keywords: upland cotton, pollen grain, ${ }^{60} \mathrm{Co}-\gamma$ ray, irradiation, agronomic trait, genetic variation

\section{Introduction}

Because of the low genetic diversity among each variety, Gossypium hirsutum L. (Malvaceae) exhibits a deficiency in heredity (Misra, et al., 2003; Datta, et al., 2001; Selvi et al, 2007; Xu, et al., 2011; Liu, et al., 2003; Iqbal, et al., 1997; Song, et al., 2004). By utilizing various mutation factors that effectively induce genetic mutations, chromosomal mutations and extra-nuclear mutations, we acquired numerous mutant types, which are not easy to obtain using general mutation methods (Sun, et al., 2006). Exposure to ${ }^{60} \mathrm{Co} \gamma$-rays is the most common mutation method applied in cotton breeding (Srivastava, et al., 2002). Fan (1980) used $\gamma$-rays and fast neutrons to treat cotton and showed improvements in cotton resistance, fiber length, fiber fineness and plant types. Gao $(2004,2006)$ established hybridization mapping of radiation mutants with respect to upland cotton by treating cotton with $\gamma$-rays at various intensities, followed by pollination. Although some progress has been made in radiation breeding, radiation-induced mutations generally develop slowly due to the emphasis on mutations and the selection of character variations obtained in the early generations after mutagenesis. In particular, the 
mechanism of ${ }^{60} \mathrm{Co} \gamma$-ray-induced mutation has not yet been reported.

Pollen grains, which are similar in size to a single cell, are haploid and contain a vegetative nucleus and one or two sperm cells. In addition, pollen grains are sensitive to mutation factors. Because mutagenesis on pollen grains generates mutations more efficiently than mutagenesis on seeds, pollen grains are considered an ideal material for use in investigating the cell biology of mutagenesis. The use of radiation to perform mutagenesis on pollen grains from crop species, including paddy rice, maize, wheat, tobacco, barley, tomatoes and soybeans, has already been reported (Koti, et al., 2004; Koti , et al., 2005).

In this study, mature upland cotton pollen grains were irradiated with ${ }^{60} \mathrm{Co} \gamma$-rays and then examined with the ultra-thin section technique and fluorescence staining. Basic variation patterns in the biological characteristics of pollination and fertilization from the perspectives of embryology and cell biology as well as variations in pollen activity were revealed by observing surface and interior structures. Based on molecular labeling, variations of DNA polymorphism in ovules acquired after pollination with radiation-treated pollen grains were studied to provide a theoretical framework for studying cotton plant type improvement and radiation-induced mutations. Furthermore, genetically based agricultural characteristics obtained in the $M_{1}$ and $M_{2}$ filial generations were analyzed to explore the rules of genetic variations in filial generations after mutagenesis.

\section{Materials and Methods}

\subsection{Plant Materials and Growth Conditions}

Field experiments were conducted using the upland cotton cultivar (Gossypium hirsutum L.) "Sumian 22" at the Institute of Plasma Physics, Chinese Academy of Science, (Hefei, China) under regular cultivation and management conditions.

\section{$2.2{ }^{60} \mathrm{Co} \gamma$ - ray Irradiation}

On a sunny day in mid-August, 2008, a healthy flower that was expected to bloom the next day was emasculated at 4:30 p.m. On the following day, stamens from the blooming flowers were collected and irradiated at the Atomic Energy Institute, Anhui Academy of Agricultural Sciences. The radiation source was ${ }^{60} \mathrm{Co} \gamma$-ray with an intensity of $20 \mathrm{~Gy}$, and the radiation dose rate was $0.48 \mathrm{~Gy} / \mathrm{min}$. Untreated pollen grains were used as the control group. Prepared pistils (without stamens) were pollinated by untreated pollen grains and $\gamma$-ray-treated pollen grains in the field. The resulting embryos were harvested one week after pollination, and the ovules were excised with scissors and dissecting needles for further examination. Mature seeds obtained from control pollen grains and radiation-treated pollen grains were harvested in October and planted in the Nanjing Jiang-Ning Experiment Base in 2009 to harvest individual $\mathrm{M}_{1}$ plants. The $\mathrm{M}_{2}$ generation was grown (row spacing: $0.8 \mathrm{~m}$; plant spacing: $0.25 \mathrm{~m}$ ) in 2010. The plant height, numbers of fruiting sites, numbers of fruiting trees, stem diameter and boll numbers were measured around September $25^{\text {th }}$ each year; the open bolls were harvested and subjected to laboratory tests around October $15^{\text {th }}$. The boll weight, lint index and seed index were also measured on approximately the same day. The dataset obtained from taxonomy was analyzed by the statistical software package SPSS 13.0.

\subsection{Scanning Electron Microscopy (SEM)}

Some of the pollen grains irradiated with the control and $\gamma$-rays were affixed onto slide platforms separately and were sprinkled with gold to be observed by SEM (RilinS-300N). For each irradiation, 200 pollen grains were observed to count the number of damaged pollen grains.

\subsection{Transmission Electron Microscopy (TEM)}

A portion of the treated pollen grains was fixed first in $4 \%$ glutaraldehyde solution and then in a mixture of glutaraldehyde and osmic acid. Later, the pollen grains were dehydrated with an alcohol and acetone gradient and embedded in epoxide resin. The thickness of the ultrathin sections was $70 \mathrm{~nm}$. The ultrastructural changes inside the pollen grains were observed using TEM (Rili H-7650).

\subsection{Simple Sequence Repeat (SSR) Analysis of Ovule DNA}

\subsubsection{Isolation of Cotton Genomic DNA}

The cetyl (or hexadecyl)-trimethyl ammonium bromide (CTAB) method was used to prepare ovule genomic DNA one week after pollination (Paterson, et al., 1993). The method was modified based on the current conditions.

\subsubsection{Microsatellite PCR Amplification}

A total of 700 pairs of primers were used in this experiment. The primer serial numbers were annotated 
according to Brookhaven National Laboratory (BNL) in the CottonDB database (http://algodon.tamu.edu/htdocs-cotton/cottondb.html) and Nanjing Agricultural University. The primers were synthesized by Invitrogen Co. Shanghai. The PCR medium contained $67 \mathrm{mmol} \cdot \mathrm{L}^{-1}$ Tris- $\mathrm{HCl}(\mathrm{pH} 8.8), 16$ $\mathrm{mmol} \cdot \mathrm{L}^{-1}\left(\mathrm{NH}_{4}\right)_{2} \mathrm{SO}_{4}, 0.2 \mathrm{mmol} \cdot \mathrm{L}^{-1}, 0.2 \mathrm{mmol} \cdot \mathrm{L}^{-1} \mathrm{dNTPs}, 2.5 \mathrm{mmol} \cdot \mathrm{L}^{-1} \mathrm{MgCl}_{2}, 0.6 \mu \mathrm{mol} \cdot \mathrm{L}^{-1}$ of both the forward and the reverse primers, $0.25 \mathrm{U}$ Taq DNA polymerase and $10 \mu 1$ template DNA. The following PCR program was used: denaturation for 2 minutes at $95^{\circ} \mathrm{C} ; 30$ cycles of denaturation for 40 seconds at $94^{\circ} \mathrm{C}$, annealing for 45 seconds at $57^{\circ} \mathrm{C}$, and elongation for 60 seconds at $72^{\circ} \mathrm{C}$; and final elongation for 10 minutes at $72^{\circ} \mathrm{C}$.

\subsubsection{Polyacrylamide Gel Electrophoresis (PAGE) and Silver Staining of the Amplified PCR Product}

Non-denaturing PAGE was performed to detect the PCR products. The gel concentration was $8 \%$; the size of the gel was $180 \times 120 \times 2 \mathrm{~mm}$; and the running buffer was $1 \times$ Tris/Borate/EDTA (or TBE). The voltage was constant during electrophoresis. The gel was cleaned with distilled water after electrophoresis. Silver staining was performed according to the standard method (Zhang, et al., 2000).

\subsection{Staining of Pollen Tubes with Decolorized Aniline Blue}

The pollen tubes in the styles were observed according to the procedure described by Yu et al. (2008) and Yue (2012). After pollination for $11 \mathrm{~h}$, the styles were harvested, fixed in an ethanol-acetic acid mixture (3:1, v/v) for $24 \mathrm{~h}$, and rehydrated with alcohol grades of $70 \%, 50 \%, 30 \%$ and $10 \%$, in series. These styles were then rinsed with $\mathrm{ddH}_{2} \mathrm{O}$, softened in a $2 \mathrm{~mol} / \mathrm{L} \mathrm{NaOH}$ solution, and stained with $0.01 \%(\mathrm{w} / \mathrm{v})$ decolorized aniline blue in 0.1 $\mathrm{mol} / \mathrm{L} \mathrm{K}_{3} \mathrm{PO}_{4}$ (pH9.0) for $12 \mathrm{~h}$. They were mounted on glass slides and spread by hand-pressing the slides for observation by fluorescence microscopy (Olympus BH-2). Video images were captured and saved. The whole staining process was repeated for at least five styles.

\section{Results and Analysis}

\subsection{Effects of ${ }^{60} \mathrm{Co}-\gamma$ Ray on the Exine Wall of Pollen Grains}

After upland cotton pollen grains were treated with $20 \mathrm{~Gy}{ }^{60} \mathrm{Co} \gamma$-rays, the outer surface morphologies of the pollen grains in the control group (natural pollen grains) and the radiation-treated pollen grains were observed with field-emission scanning electron microscopes. The outer wall structure of the pollen in the control group was tightly compact and displayed a circular form. A high density of prickles with a regular arrangement on the outer wall was observed. Numerous germ pores were symmetrically and regularly arrayed on the pollen wall. Germ furrows were found within the germ pores in the mature pollen (Figure 1-A). No damage to the outer wall was found after the ${ }^{60} \mathrm{Co} \gamma$-ray treatment compared to the control group (Figure 1-B).
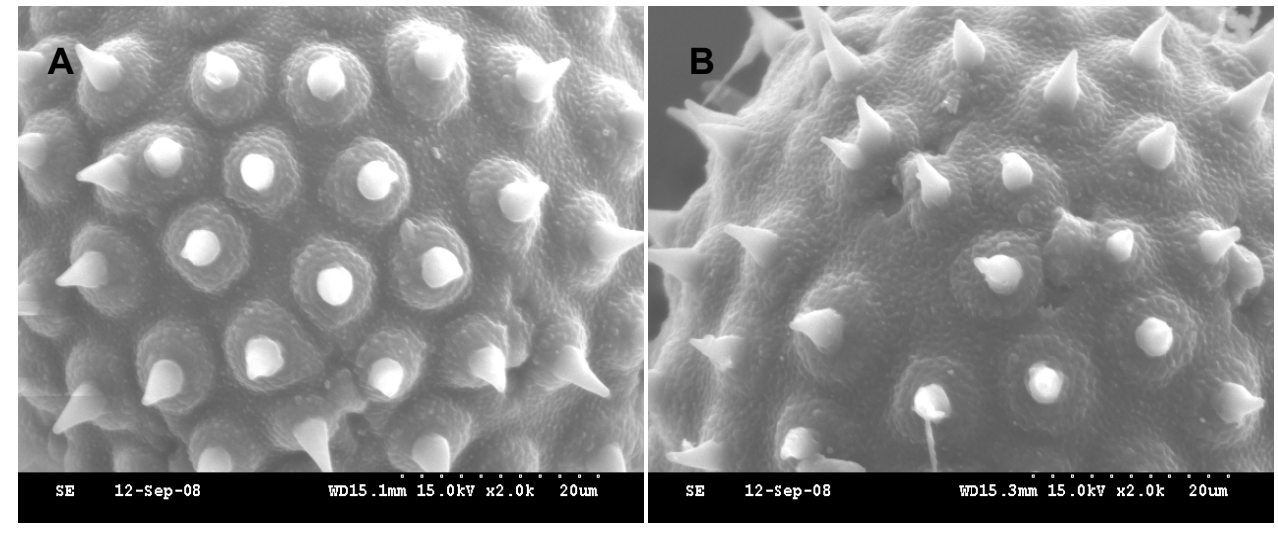

Figure 1. Configuration SEM images of pollen grains treated with 20 Gy $\gamma$-rays

Picture A: Control pollen grains $(2000 \times)$. Pictures B: Pollen grains treated with 20 Gy $\gamma$-rays $(2000 \times)$.

\subsection{Effects of ${ }^{60} \mathrm{Co}-\gamma$ Ray on the Interior Ultrastructure of Pollen Grains}

The ultra-thin section technique was performed randomly on the control group (natural pollen grains) and radiation-treated pollen grains, respectively, after upland cotton pollen grains were treated with ${ }^{60} \mathrm{Co} \gamma$-rays at an intensity of $20 \mathrm{~Gy}$. The interior anatomical structure of the pollen was observed by transmission electron microscopy to reveal structural variations. Experimental observation indicated that the two-layer internal and external walls stayed tightly together with a regular arrangement (Figure 2-A). However, after the ${ }^{60} \mathrm{Co} \gamma$-ray treatment, the internal wall of the pollen became thinner and was irregularly shaped, with partial concavities, 
compared to the control group (Figure 2-B). The cytoplasm from the pollen in the control group exhibited high compactness, within which ribosomes, the endoplasmic reticulum, mitochondria and plasmids were found to have intact structures and in large quantities. Moreover, large numbers of starch granules and liposomes and a few small vacuoles were also found in the cytoplasm (Figure 2-C). Circular structures composed of numerous plasmids and small, membrane-enclosed vacuoles were also observed (Figure 5-D). In contrast, the quantity of the contents and the compactness in radiation-treated pollen increased, and the cytoplasm showed slight degradation. Plasmids located in small, circular vacuoles displayed increases in volume and decreases in quantity (Figure 2-E, F). In addition, large numbers of the endoplasmic reticula exhibited depolymerization (Figure 2-G, $\mathrm{H})$, and the number of mitochondria decreased.
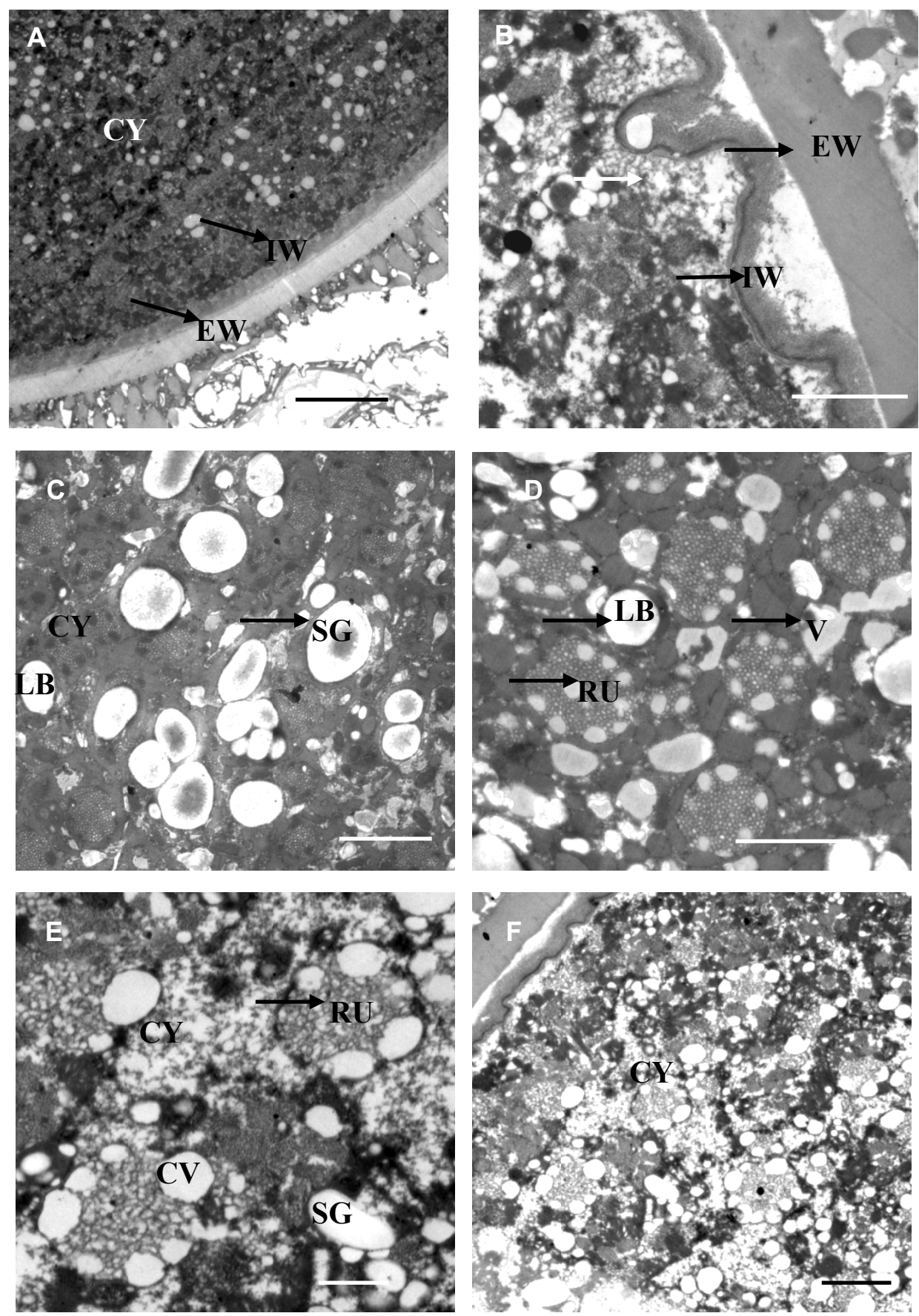

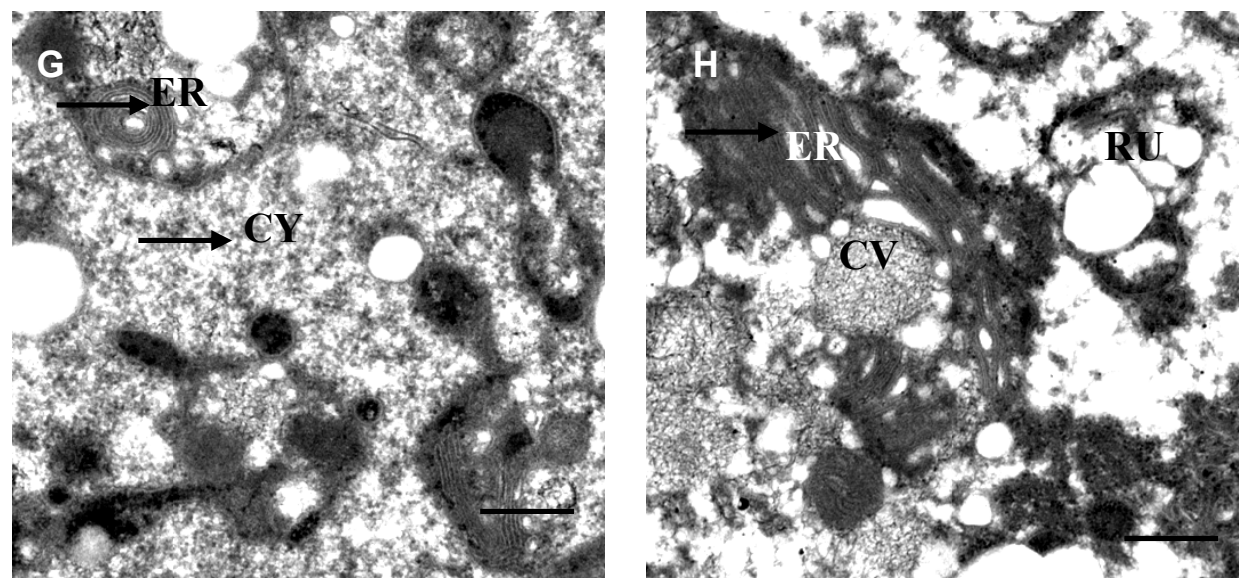

IW, interior wall; EW, exine wall; RU, round vesicle; SG, starch grain; CY, cytoplasm; CV, coated vesicle; V, vacuole; LB, lipid body; ER, endoplasmic reticulum

Figure 2. TEM images of changes in the interior structure of pollen grains treated with $20 \mathrm{~Gy} \gamma$-rays (section thickness $=70 \mathrm{~nm}$ )

Pictures A, C, D: Control pollen grains (Arrow in A shows that the exine and inner wall of control are arranged regularly, $700 \times, \mathrm{Bar}=50 \mu \mathrm{m}$. Arrows in $\mathrm{C}$ show that the densely distributed cytoplasm abounds with ribosomes, endoplasmic reticulum, mitochondria, plastids, liposomes, starch grains and a few small vacuoles, $1500 \times$, Bar $=$ $20 \mu \mathrm{m}$. Arrow in D show a round-like unit, 2500×, Bar $=20 \mu \mathrm{m}$ ). Picture B, E, F, G and H: 20 Gy $\gamma$-rays-treated pollen grains (B: 2500×, Bar $=20 \mu \mathrm{m}$; E: $1000 \times, \mathrm{Bar}=10 \mu \mathrm{m} ; \mathrm{F}: 1200 \times, \mathrm{Bar}=20 \mu \mathrm{m} ; \mathrm{G}: 6000 \times, \mathrm{Bar}=5 \mu \mathrm{m}$; $\mathrm{H}: 6000 \times, \mathrm{Bar}=5 \mu \mathrm{m})$.

\subsection{Effects of ${ }^{60} \mathrm{Co}-\gamma$ Ray on the Vigor of Pollen Grains}

The vigor of the control and the $\gamma$-rays irradiated pollen grains was evaluated by counting pollen tubes in the styles which were stained with decolorized aniline blue. The average number of pollen tubes in the styles after pollination with control pollen grains (Figure 3-A) was 694.25; the average number of tubes in 20 Gy $\gamma$-rays irradiated grains (Figure 3-B) was 430.44, which was decreased by $38 \%$ than the control. There was a significant difference $(p<0.01)$ in the germination rate between the control and the irradiated group.
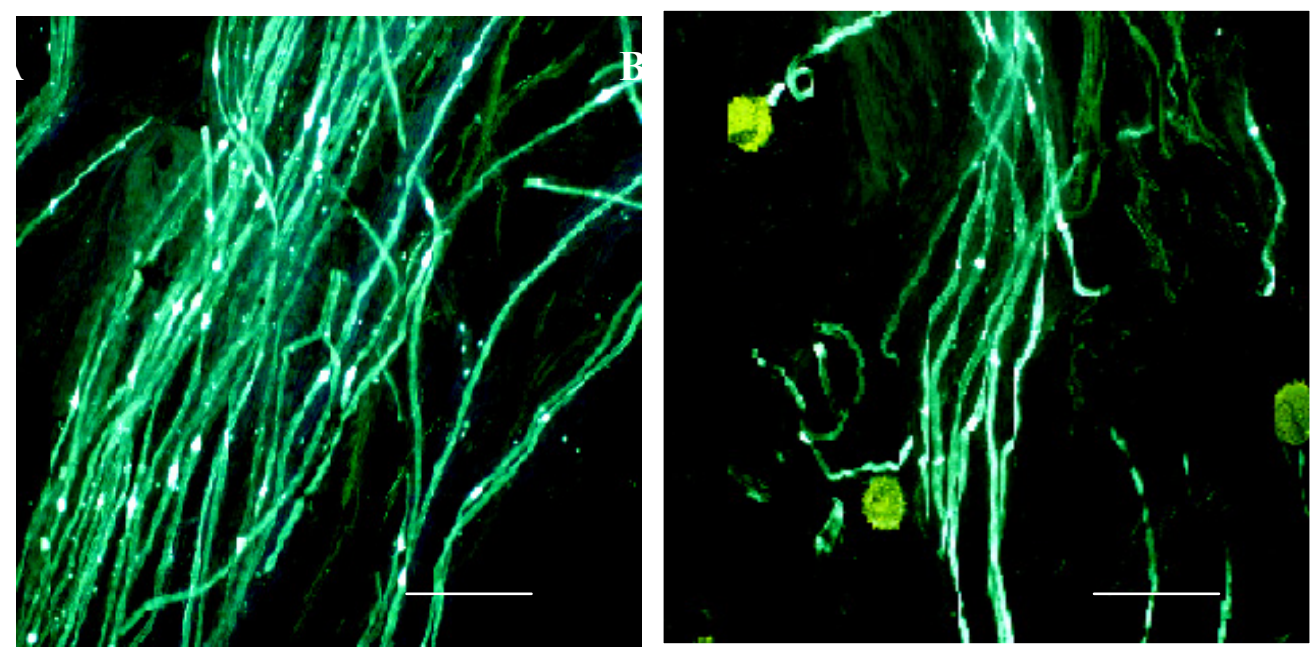

Figure 3. Pollen tubes in styles pollinated with $\gamma$-ray-irradiated grains

A: Pollen tubes in a style pollinated with control pollen grains $(320 \times$, bar $=90 \mu \mathrm{m})$. B: Pollen tubes in a style pollinated with $20 \mathrm{~Gy} \gamma$-ray-treated pollen grains $(320 \times$, bar $=100 \mu \mathrm{m})$.

\subsection{SSR Labeling of the $M_{1}$ Generation (ovule) after the ${ }^{60}$ Co $\gamma$-ray Treatment}

Pollen grains were irradiated with ${ }^{60} \mathrm{Co} \gamma$-rays at an intensity of $20 \mathrm{~Gy}$, and ovules pollinated with the irradiated pollen grains were grown for 7 days after pollination and used as the materials for genomic DNA isolation. Using this genomic DNA as a template, SSR labeling was performed with 700 random primer pairs (Figure 4). 
The SSR results indicated that DNA polymorphism from the radiation-treated samples (value 0.20 ) demonstrated only a slight similarity with the control group; in other words, dramatic differences were found between the two groups $(\mathrm{p}<0.01)$. This observation demonstrated that the cobalt irradiation of pollen had an impact on ovule DNA polymorphism and altered the genetic material in pollen to a certain extent.

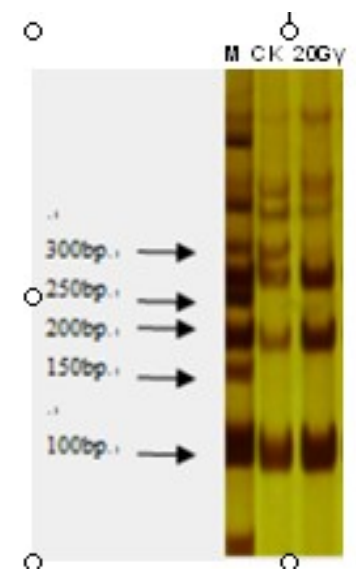

Figure $4.10 \%$ polyacrylamide gel electrophoresis

M-Marker, CK-the control, 20Gy-the $\gamma$ rays irradiated

\subsection{Effects on $M_{1}$ Agricultural Characteristics after the ${ }^{60}$ Co- $\gamma$ Ray Treatment}

Pollination with the ${ }^{60} \mathrm{Co} \gamma$-ray-treated (intensity: $20 \mathrm{~Gy}$ ) pollen grains and the pollen in the control group (natural pollen grains) was performed in the field. After the harvest, a portion of the seeds were planted at room temperature (hydroponics) for further seed germination and the observation of the early growth of the seedlings. The numbers of seeds that had germinated were assessed after 7 days. The germination rate showed a $41.03 \%$ decrease in the irradiated group compared to the control group. Other indexes, such as the root length, the number of roots and the hypocotyl length, were measured after 20 days. The statistics indicated that the length of the main root, the maximum root length, the average root length, the lateral root number and the seedling height decreased by $22.24 \%, 18.93 \%, 11.80 \%, 28.02 \%$ and $23.05 \%$, respectively, suggesting that ${ }^{60} \mathrm{Co} \gamma$-rays had certain damaging effects on cotton pollen grains.

Other seeds were planted in the field to produce the $\mathrm{M}_{1}$ generation. Field investigation and laboratory tests were performed on each individual $\mathrm{M}_{1}$ plant (Table 1). The results indicated that various mutants were found in the filial generations treated with $\gamma$-rays, among which $56.7 \%$ were sterile and $43.3 \%$ were fertile compared to the control group. As shown in Table 1, the average values obtained from eight indexes, including the boll numbers, plant height, the number of fruiting plants, the number of fruiting branches, the stem diameter, the maximum fruiting branches, the lint index and the seed index, decreased compared to the control group. Among these indexes, the coefficient of variation from the boll numbers had the largest value $(119.79 \%)$, which increased by $103.206 \%$ (variation range: 0-89 [unit]) compared to the control group. The coefficients of variation from the lint index, the stem diameter, the seed index, the numbers of fruiting branches, the maximum fruiting branch and the numbers of fruiting trees were $74.588 \%, 75.96 \%, 69.83 \%, 33.25 \%, 29.624 \%$ and $16.255 \%$ higher compared to the values of the control group, respectively, and the mutation rates were above $25.000 \%$. In contrast, the coefficient of variation of plant height had the smallest value (20.154\%), which increased by $11.843 \%$ (variation range: $36.2-130.5$ [unit]) compared to the control group. The variations in each agricultural characteristic also increased compared to the control group, indicating that the ${ }^{60} \mathrm{Co} \gamma$-rays not only affected the vegetative growth of cotton filial generations but also the reproductive growth, which led to alterations of each characteristic, with great variation. Furthermore, the radiation mutagenesis exhibited diverse effects on different characteristics in upland cotton; certain characteristics, e.g., the boll numbers, the lint index and the seed index, were relatively sensitive to radiation.

The t-test result indicated that the values obtained from the numbers of fruiting sites, the lint index, the seed index, the numbers of fruiting trees, the boll numbers, the plant height and the maximum fruiting branches showed remarkable significance $(\mathrm{p}<0.01)$, and the value from the stem diameter exhibited significance $(\mathrm{p}<0.05)$ compared to the control group. 
Table 1. Effects on $\mathrm{M}_{1}$ agricultural characteristics after the ${ }^{60} \mathrm{Co}-\gamma$ ray treatment

\begin{tabular}{|c|c|c|c|c|c|c|c|c|c|}
\hline Parameter & & $\begin{array}{l}\text { Boll } \\
\text { number }\end{array}$ & $\begin{array}{l}\text { Height } \\
(\mathrm{cm})\end{array}$ & $\begin{array}{l}\text { Fruiting } \\
\text { plants } \\
\text { number }\end{array}$ & $\begin{array}{l}\text { Fruit } \\
\text { branch } \\
\text { number }\end{array}$ & $\begin{array}{l}\text { Perimeter of } \\
\text { stem }(\mathrm{cm})\end{array}$ & $\begin{array}{l}\text { Longissimus } \\
\text { fruit branch } \\
(\mathrm{cm})\end{array}$ & $\begin{array}{l}\text { Lint } \\
\text { percent-age } \\
(\%) \\
\end{array}$ & $\begin{array}{l}\text { Seed index } \\
(\mathrm{g})\end{array}$ \\
\hline \multirow{2}{*}{$\frac{3}{8}$} & CK & 27.732 & 107.317 & 16.976 & 96.488 & 8.939 & 85.937 & 41.1 & 9.877 \\
\hline & $20 \mathrm{~Gy}$ & 10.522 & 88.726 & 15.384 & 90.968 & 8.208 & 53.498 & 26.6 & 6.473 \\
\hline \multirow{2}{*}{ 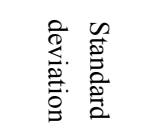 } & $\mathrm{CK}$ & 4.599 & 8.920 & 1.891 & 6.388 & 0.409 & 4.097 & 3 & 0.918 \\
\hline & $20 \mathrm{~Gy}$ & 12.604 & 17.881 & 4.214 & 36.065 & 6.610 & 18.399 & 21.7 & 5.121 \\
\hline \multirow{2}{*}{ 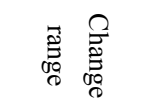 } & CK & $20-35$ & $88.2-128.6$ & $10-22$ & $87-115$ & $8.2-10$ & $79-98$ & $32.8-47$ & $8.68-11.82$ \\
\hline & 20Gy & $0-89$ & $36.2-130.5$ & $0-26$ & $0-212$ & $2.9-89$ & $0-107$ & $0-143.1$ & $0-18.4$ \\
\hline \multirow{2}{*}{ 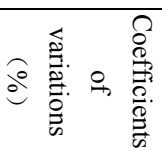 } & CK & 16.584 & 8.311 & 11.137 & 6.620 & 4.578 & 4.768 & 7.261 & 9.290 \\
\hline & 20Gy & 119.79 & 20.154 & 27.392 & 39.645 & 80.538 & 34.392 & 81.849 & 79.12 \\
\hline
\end{tabular}

\subsection{Effects on $\mathrm{M}_{2}$ Agricultural Characteristics after the ${ }^{60}$ Co- $\gamma$ Ray Treatment}

Individual $\mathrm{M}_{1}$ plants with extreme phenotypes resulting from the ${ }^{60} \mathrm{Co} \gamma$-ray treatment (intensity: $20 \mathrm{~Gy}$ ) were eliminated after the harvest. Other individuals were grown until the following year and were considered the $\mathrm{M}_{2}$ generation. Field investigation and laboratory tests were performed on each individual $\mathrm{M}_{2}$ plant (Table 2). The experimental results indicated that certain differences with respect to agricultural characteristics were still found in the $\mathrm{M}_{2}$ generation compared to the control group, among which $24 \%$ were sterile and $76 \%$ were fertile. As shown in Table 2, the average values from five indexes, including plant height, the number of fruiting branches, the boll numbers, the yield and the lint index were less than the values of the control group; however, no difference was found regarding the boll weight. The coefficient of variation from the boll numbers had the largest value (33.081\%), which increased by $21.944 \%$ (variation range: $5-90$ [unit]) compared to the control group; the coefficients of variation for the seed cotton yield, the number of fruiting branches, plant height and the single-boll weight increased by $16.261 \%, 3.827 \%, 3.986 \%$ and $7.25 \%$, respectively, compared to the control group. In contrast, the coefficient of variation from the lint index displayed the smallest value $(4.899 \%$; less than $10 \%$ ), which increased by $0.497 \%$ (the variation range: $34-51.4$ [unit]) compared to the control group. The variations in each agricultural characteristic also were elevated compared to the control group, indicating that ${ }^{60} \mathrm{Co} \gamma$-rays caused dwarfing effects on $\mathrm{M}_{2}$ cotton and positive and negative effects on the single-boll weight and the number of fruiting branches; however, the coefficient of variation and the variation range for each agricultural characteristic were less than in the $\mathrm{M}_{1}$ generation. The t-test result indicated that the values obtained from the $\mathrm{M}_{2}$ generation with respect to plant height, the single-boll weight, the number of fruiting branches, the boll numbers and the seed cotton yield demonstrated remarkable significance $(p<0.01)$ and that the value from the lint index exhibited significance $(\mathrm{p}<0.05)$ compared to the control group.

Table 2. Effects on $\mathrm{M}_{2}$ agricultural characteristics after the ${ }^{60} \mathrm{Co}-\gamma$ ray treatment

\begin{tabular}{|c|c|c|c|c|c|c|c|}
\hline Parameter & & $\begin{array}{l}\text { Height } \\
(\mathrm{cm})\end{array}$ & $\begin{array}{l}\text { Fruit } \\
\text { branch } \\
\text { number }\end{array}$ & $\begin{array}{l}\text { Boll } \\
\text { number }\end{array}$ & $\begin{array}{l}\text { Seed cotton } \\
\text { yield }(\mathrm{g} / \text { line })\end{array}$ & $\begin{array}{l}\text { Boll weight } \\
\text { (g) }\end{array}$ & $\begin{array}{l}\text { Lint } \\
\text { percentage } \\
(\%) \\
\end{array}$ \\
\hline \multirow{2}{*}{ 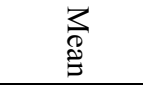 } & $\mathrm{CK}$ & 107.55 & 15.5 & 36.45 & 1382.567 & 5.508 & 45 \\
\hline & 20Gy & 89.526 & 13.11 & 20.63 & 1198.514 & 5.031 & 44.7 \\
\hline \multirow{2}{*}{ 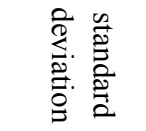 } & $\mathrm{CK}$ & 9.660 & 1.504 & 2.856 & 81.112 & 0.254 & 2 \\
\hline & 20Gy & 11.7 & 1.774 & 6.825 & 288.7978 & 0.597 & 2.2 \\
\hline \multirow{2}{*}{ 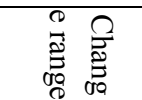 } & $\mathrm{CK}$ & $80-130$ & $14-19$ & $30-41$ & $1325.4-1475.4$ & $5.295-5.79$ & $43.4-47.2$ \\
\hline & 20Gy & $28-180$ & $5-22$ & $5-90$ & $369.6-1811.3$ & $1.76-6.925$ & $34-51.4$ \\
\hline \multirow{2}{*}{ 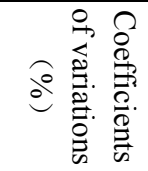 } & $\mathrm{CK}$ & 8.982 & 9.706 & 11.137 & 7.835 & 4.620 & 4.402 \\
\hline & 20Gy & 12.968 & 13.533 & 33.081 & 24.096 & 11.870 & 4.899 \\
\hline
\end{tabular}




\section{Discussion}

Mutation breeding is currently the most common and efficient method in advanced plant breeding. Physical mutagenesis is widely applied in plant breeding due to its advantages, such as the high mutation rate, low number of chromosome aberrations, wide range of mutations and reduced damage compared to chemical mutagenesis. Among these methods, numerous successful studies in agriculture reported that $\gamma$-rays have a powerful capacity for transmission, which causes strong biological effects in advanced plants (Huang, et al., 1999; Cai, et al., 2000; Sanam' ian, 2003; Selvi, et al., 2007). However, there is a lack of systematic studies on the ${ }^{60} \mathrm{Co} \gamma$-ray mechanism in cells in combination with the investigation of agricultural characteristics in the filial generations after mutagenesis. In this study, upland cotton pollen grains were used to investigate the ${ }^{60} \mathrm{Co} \gamma$-ray induced mutagenesis mechanism in pollen grains based on studies regarding aspects of cell biology, molecular labeling and mutagenic rules of agricultural characteristics in the $\mathrm{M}_{1}$ and $\mathrm{M}_{2}$ generations. Raut and Sainis (2012) indicate that $\gamma$ radiation induced DNA damage and repair in wheat seedlings and initiated differential acetylation of $\mathrm{H} 3$ and H4. This is the first report in plants on site-specific $\mathrm{H} 3$ and $\mathrm{H} 4$ modifications in response to exposure to ionizing radiation.

The experimental results indicated that no abrasion effect caused by the ${ }^{60} \mathrm{Co} \gamma$-rays was found on the pollen surface; however, ${ }^{60} \mathrm{Co} \gamma$-rays were able to induce dramatic internal structure variations in the pollen grains. This phenomenon might be due to $\gamma$-rays, which are a type of high-energy irradiation. Because of the short wavelength (0.001-0.0001 nm), powerful transmission capacity and equal distribution, $\gamma$-rays cause ionization through collisions with radiation-sensitive locations in pollen cells, causing obvious alterations in the internal structures. Because certain alterations are not able to be repaired and are consequently transmitted in the genetic material, efficient mutations can be acquired.
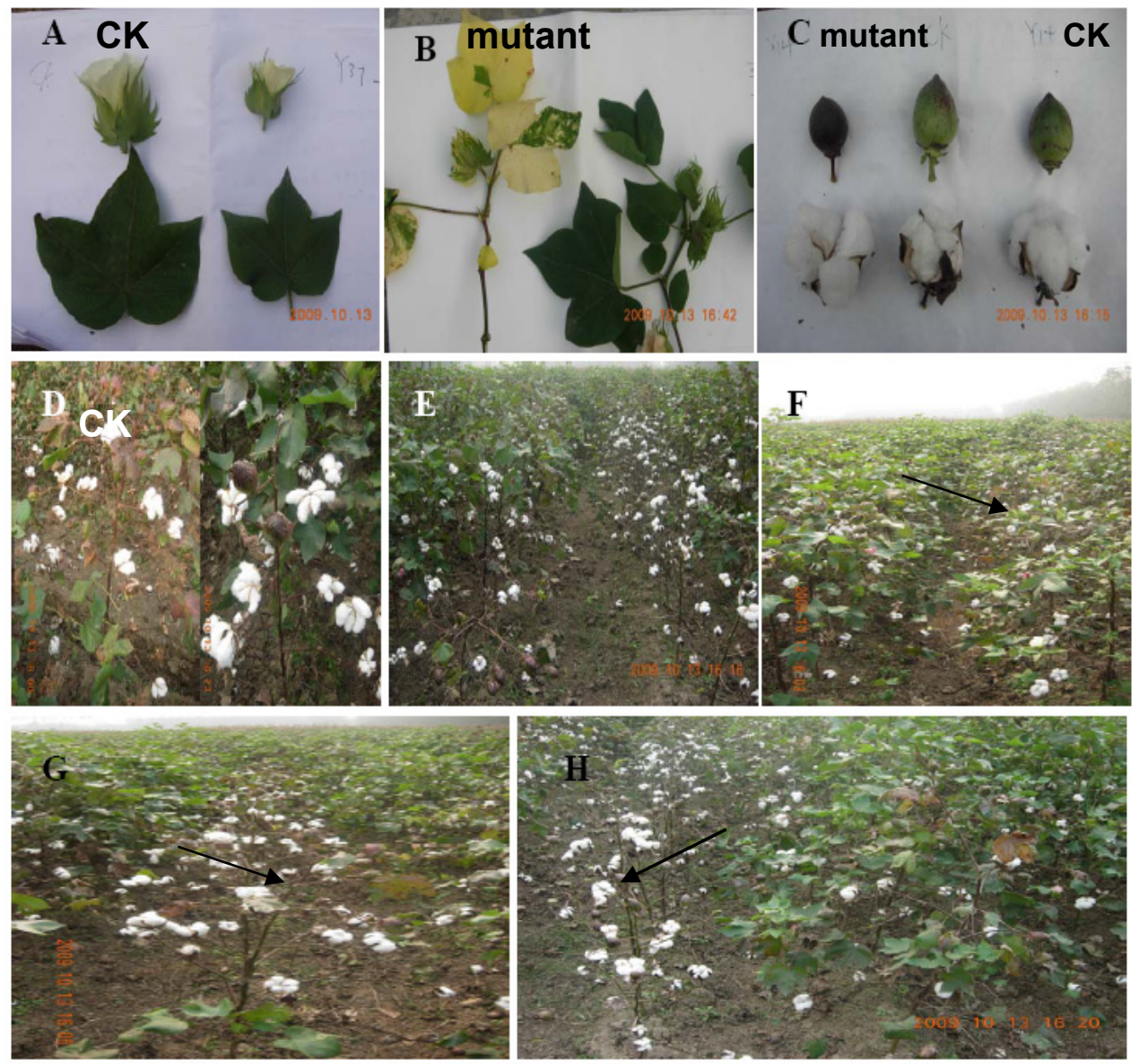

Figure 5. Types of qualitative characters mutants in the progeny

Picture A: The flower and leaves of the mutant become smaller than that of the control. Pictures B: The leaves of the mutant become more yellow than that of the control. Pictures C: The cotton boll of the mutant become smaller than that of the control. Pictures D: The opening of cotton bolls of the mutant become better than that of the control. Pictures E-H: The plant progeny row of the mutant apparent stability 
Our experimental results showed that the decreases in pollen activity and the emergence rate in the M1 generation after the 60Co $\gamma$-ray (intensity: $20 \mathrm{~Gy}$ ) treatment of upland cotton pollen grains were consistent with those obtained by $\mathrm{Hu}$ (1996). After the radiation treatment, SSR labeling of ovule polymorphism after pollination showed differences compared to the control group, which indicated that 60Co $\gamma$-rays exerted effects on pollen DNA polymorphism; in other words, characteristics of the DNA sequence might have changed. Various mutations with obvious qualitative characteristics occurred in individual plants (Figure 5); variations resulting in different positive and negative effects were found in agronomic characteristics, e.g., the boll numbers, boll weight, plant height, the lint index, the stem diameter and the number of fruiting branches. Variations resulting from positive and negative effects on the boll weight, the yield, plant height and the number of fruiting branches were still observed in the M2 cotton; however, the variation range and the coefficients of variation were significantly decreased compared to the $\mathrm{M}_{1}$ generation, which indicates that the alterations had partially disappeared in the $\mathrm{M}_{2}$ generations. This phenomenon suggests that not all of the variations shown in the $\mathrm{M}_{1}$ generation are real genetic mutations. Partial variations resulting from metabolic disorders occur due to physical damage. Some types of damage cannot be transmitted to subsequent generations because it can be ameliorated through self-repair in organisms. Moreover, no significant qualitative variations were found in the $\mathrm{M}_{2}$ generations. Certain economic variations found in the $\mathrm{M}_{2}$ generation might result either from the $\mathrm{M}_{1}$ generation or residual variations caused by radiation. Therefore, 'selection from advanced generations is necessary to ensure stable genetic mutants.

\section{Acknowledgements}

This work was supported by t the Science and Technology Development foundation Program of University in Tianjin (20110603, 20100606), Doctoral Foud of Tianjin Normal University (52XB1105) and Open Foud of Tianjin Key Lab Cytogenet \& Mol Regulat.

\section{References}

Cai, L. (2000). The Application of Radiation Breeding Technique in Plant Resistance Breeding. Auhui Agricultural Science Bulletin 6(6), 44-55 (in Chinese). http://www.cnki.com.cn/Article/CJFDTotal-AHNB200006019.htm

Datta, S. K., Chakrabarty, D., \& Mandal, A. K. A. (2001). Gamma Ray Induced Genetic Manipulations in Flower Colour and Shape in Dendranthema Grandiflorum and Their Management through Tissue Culture. Plant Breed, 120(1), 91-92. http://dx.doi.org/10.1046/j.1439-0523.2001.00553.x

Fan, P. (1980). Phenotypic Variation Effect of Gamma Irradiation on Cotton. Acta Agriculturae Nucleatae Sinica, 1, 13-19 (in Chinese). http://wuxizazhi.cnki.net/Search/HNXB198001004.html

Gao, W., Chen, Z. J., Yu, J. Z., Kohel, R. J., Womack, J. E., \& Stelly, D. M. (2006). Wide-Cross Whole-Genome Radiation Hybrid Mapping of the Cotton (Gossypium barbadense L.) Genome. Mol Genet Genomics, 275(2), 105-113. http://dx.doi.org/10. 1007 / s00438 - 005-0069-5

Gao, W. X., Chen, Z. J., Yu, J. Z., Raska, D., \& Kohel, R. J. (2004). Wide-Cross Whole-Genome Radiation Hybrid Mapping of Cotton (Gossypium hirsutum L.). Genetics, 167(3), 1317-1329. http://dx.doi.org/10.1534/genetics.103.020479

Hu, B. M., Zhang, T. Z., \& Pan, J. J. (1996). Study on Biological and Cytological Effects of Hybrids Pollinated with Irradiated Pollen in Upland Cotton. Acta Agriculturae Nucleatae, 10(1), 16-20 (in Chinese). http://www.hnxb.org/CN/abstract/abstract9837.shtml

Huang, B. C., Miao, B. L., \& Zhang, Z. M. (1999). Mutation Breeding of Rice Quality. Jiangsu Agricultural Sciences, 3, 15-16 (in Chinese). www.cnki.com.cn/Article/CJFDTOTAL-JSNY903.004.htm

Iqbal, M. J., Aziz, N., Saeed, N. A., et al. (1997). Genetic Diversity Evaluation of Some Elite Cotton Varieties by RAPD Analysis.Theoretical and Applied Genetics, 94, 139-144. http://dx.doi.org/10.1007/s001220050392

Koti, S., Reddy, K. R., Reddy, V. R., Kakani, V. G., \& Zhao, D. (2005). Interactive Effects of Carbon Dioxide, Temperature, and Ultraviolet-B Radiation on Soybean (Glycine max L.) Flower and Pollen Morphology, Pollen Production, Germination, and Tube Lengths. Journal of Experimental Botany, 56, 725-736, http://dx.doi.org/10.1093/jxb/eri044

Koti, S., Reddy, K. R., kakani, V. G., Zhao, D., \& Reddy, V. R. (2004). Soybean (Glycine max) Pollen Germination Characteristics, Flower and Pollen Morphology in Response to Enhanced Ultraviolet - B Radiation. Annals of Botany, 94(6), 855-864. http://dx.doi.org/10.1093/aob/mch212 
Liu, W. X., Kong, F. L., Guo, Z. L., Zhang, Q. Y., Peng, H. R., Fu, X. Q., \& Yang, F. X. (2003). An Analysis about Genetic Basis of Cotton Cultivars in China since 1949 with Molecular Markers. Acta Genetica Sinica 30(6), 560-570 (in Chinese). http://www.cqvip.com/qk/95085x/200306/7876257.html

Misra, P., Datta, S. K., \& Chakrabarty, D. (2003). Mutation in Flower Colour and Shape of Chrysanthemum Morifolium Induced by $\gamma$-Radiation. Biologia Plantarum, 47(1), 153-156. http://dx.doi.org/0.1023/A:1027365822769

Paterson, A. H., Brubaker, C. L., \& Wendel, J. F. (1993). A rapid Method for Extraction of Cotton Genomic DNA Suitable for RFLP or PCR Analysis. Plant Mol Biol Rep, 11(2), 122-127. http://dx.doi.org/10.1007/BF02670470

Raut, V. V., \& Sainis, J. K. (2012). ${ }^{60} \mathrm{Co}-\gamma$ radiation induces differential acetylation and phosphorylation of histones $\mathrm{H} 3$ and $\mathrm{H} 4$ in wheat. Plant Biology, 14, 110-117. http://dx.doi.org/10.1111/j.1438-8677.2011.00463.x

Sanam' ian, M. F. (2003). Evaluation of the Effect of Pollen Irradiation on Karyotype Variability in M2 Cotton Plants. Genetika, 39(8), 1081-1090. http://dx.doi.org/10.1023/A:1025330823281

Selvi, B. S., Ponnuswami, V., \& Sumathi, T. (2007). Genetic Variability Studies in Gamma Ray Induced Amla (Emblica officinalis Gaertn.) Grafts. J. Appl. Sci. Res., 3(12), 1929-1932. http://www.aensionline.com/jasr/jasr/2007/1929-1932.pdf

Song, X. L., Sun, X. Z., Zhang T. Z., \& Wang H. G. (2004). Advances on Genetic Diversity of Cotton (Gossypium). Acta Botanica Boreali-occidentalia Sinica, 24(12), 2393-2397 (in Chinese). http://www.cqvip.com/qk/94431x/200413/11156152.0.html

Srivastava, P., Singh, R. P., Srlvastava, P., \& Misra, R. L. (2002) Effect of Gamma Radiation $\left({ }^{60} \mathrm{Co}\right)$ on Gladiolus Floriculture Research Trend in India [C]. Proceeding of the national symposium on India

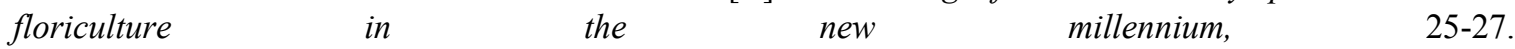
http://scholar.google.com/scholar?q=Effect + of + Gamma+Radiation+\%2860Co\%29+on+Gladiolus+Floricul ture+Research+Trend + in + India\&hl=zh-CN\&btnG=\%E6\%90\%9C\%E7\%B4\%A2\&lr=

Sun, J. L., Du, X. M., Zhou, Z. L., Pan, Z. E., \& Pang, B. Y. (2006). Law of Genetic Variation of the Progeny of Cotton (Gossypium hirsutum L.) Irradiated by $\gamma$ Ray. Acta Agriculturae Boreali-Sinica, 21(2), 27-33. (in Chinese). http://www.cqvip.com/qk/91494x/20062/21742393.0.html

Xu, Q. H., Zhang, X. L., \& Nie, Y. C. (2011). Genetic Diversity Evaluation of Cultivars (G. hirsumtum L.) from the Changjiang River Valley and Tellow River Valley by RAPD Markers. Acta Genetica Sinica, 28(7), 683-690. (in Chinese). $\mathrm{http}: / /$ www.cnki.net $/ \mathrm{kcms} /$ detail/detail.aspx?dbcode $=$ cjfq\&dbname $=$ cjfq2001\&filename $=y \mathrm{cxb} 200107014 \&$ uid=WEEvREcwSIJHSldTTEYzVDlpRVkvV2VJdmUxMEIzVU81OE12UjIzK2xrdWRhdzdSWTNkVWs xbS9TSWgzUTljPQ==\&p

Yu, Y. J., Wu, L. J., Wu, Y. J., Wang, Q. Y., \& Tang, C. M. (2008). The Damaging Effects of Nitrogen Ion Beam Irradiation on Upland Cotton (Gossypium hirsutum L.) Pollen Grains. Nucl. Instr. and Meth. Phys. Res. B, 266(18), 3959-3967. http://dx.doi.org/10.1016/j.nimb.2008.06.036

Yue, J. Y., Wu, L. J., Wu, Y. J., \& Tang, C. M. (2002). Alpha-particles and ${ }^{60} \mathrm{Co} \gamma$-rays Have Different Biological Effects on Upland Cotton (Gossypium hirsutum L.) Pollen Grains. Journal of Agricultural Science, 4(3), 137-141. http://www.ccsenet.org/journal/index.php/jas/article/view/11669

Zhang, J., Wu, Y. T., Guo, W. Z., \& Zhang, T. Z. (2000). Fast Screening of Microsatellite Markers in Cotton with PAGE/silver Staining. Acta Gossypii Sinica, 12(5), 267-269 (in Chinese). http://www.cqvip.com/qk/98108x/200005/4955486.html 